\title{
Identification and Characterization of Banana Bract Mosaic Virus in India
}

\author{
B. C. Rodoni, Centre for Molecular Biotechnology, Queensland University of Technology (QUT), GPO Box 2434, \\ Brisbane, Australia, 4001; Y. S. Ahlawat and A. Varma, Division of Plant Pathology, Indian Agricultural Research \\ Institute, New Delhi-110 012, India; and J. L. Dale and R. M. Harding, Centre for Molecular Biotechnology, \\ QUT, GPO Box 2434, Brisbane, Australia, 4001
}

\begin{abstract}
Rodoni, B. C., Ahlawat, Y. S., Varma, A., Dale, J. L., and Harding, R. M. 1997. Identification and characterization of banana bract mosaic virus in India. Plant Dis. 81:669-672.

We have identified banana bract mosaic potyvirus (BBMV) in banana plants growing in the Coimbatore and Tiruchchirappalli regions of southern India based on symptomatology, particle morphology, sequence homology, and nucleic acid hybridization assays. Potyvirus-like particles typical of BBMV also were detected in sap dips from banana plants growing in Maharashtra State. Sequence comparisons of the C terminus of the coat protein-coding and 3' untranslated regions revealed that the Indian isolates of BBMV had greater than 96.6 and $97.2 \%$ homology with a Philippines isolate at the nucleotide and amino acid levels, respectively. BBMV-infected banana cultivars from the Coimbatore region showed the characteristic mosaic on the bract of the banana inflorescence. In contrast, infected plants growing in the Tiruchchirappalli region and Maharashtra State displayed symptoms similar to those associated with cucumber mosaic cucumovirus and not the characteristic bract mosaic symptom. These results indicate that BBMV is more widespread than previously thought.
\end{abstract}

Banana bract mosaic potyvirus (BBMV) is a recently described, nonpersistently aphidtransmitted virus of bananas that causes yield losses of up to $40 \%(3,7)$. The previously described symptoms of the disease include discontinuous streaks on the bract of the banana inflorescence, spindle-shaped streaks that are irregularly scattered along the petiole, and, on removal of dead leaf sheaths, a mottled discoloration on the pseudostem (12). BBMV has been classified as a potyvirus based on (i) a particle morphology of flexuous rods measuring 660 to $760 \mathrm{~nm}$, (ii) a $38-\mathrm{kDa}$ coat protein that reacts with a general potyvirus antisera, and (iii) sequence homology of the C-terminal half of the coat protein-coding and $3^{\prime}$ untranslated regions with other potyviruses, including ornithogalum mosaic and maize dwarf mosaic potyviruses (3).

BBMV has been reported only in the Philippines (8), where it spread throughout the country in a relatively short period of time (12). The virus poses a considerable quarantine risk due to its limited distribution and its ability to spread either through vegetative plant parts or by aphids. With an increase in the international movement of banana germplasm in recent years, it is important that the distribution of BBMV

Corresponding author: R. M. Harding

E-mail: r.harding@qut.edu.au

Accepted for publication 7 March 1997

Publication no. D-1997-0428-04R

(C) 1997 The American Phytopathological Society be determined. It is possible that BBMV is present in other countries, because uncharacterized potyvirus-like particles have been observed in bananas from Costa Rica, India, and several African countries, including Uganda, Ghana, Zanzibar, and South Africa $(1,14,16)$

The objective of this study was to determine if BBMV is present in India and, if so, to determine its relationship to the BBMV isolate present in the Philippines.

\section{MATERIALS AND METHODS}

Purification and electron microscopy. Banana leaves showing symptoms of BBMV and cucumber mosaic cucumovirus (CMV) were collected from the Coimbatore and Tiruchchirappalli regions in the Tamil Nadu Province of southern India and from the Pune region of Maharashtra State. BBMV was purified from fresh or frozen $\left(-70^{\circ} \mathrm{C}\right)$ banana leaves using a recently developed protocol (J. Thomas, unpublished data), and virions were resuspended in $0.05 \mathrm{M}$ borate buffer, $\mathrm{pH} 6.8$, and stored at $-70^{\circ} \mathrm{C}$.

Purified virus preparations and banana sap dips were negatively stained with $2 \%$ potassium phosphotungstate and $2 \%$ uranyl acetate, respectively, and examined with a JEOL (Tokyo) 1200 EX transmission electron microscope.

RNA extraction, reverse transcription (RT), and polymerase chain reaction (PCR). RNA was extracted from 2 to $3 \mathrm{~g}$ of leaf tissue (4), resuspended in sterile water, and analyzed spectrophotometrically for purity and concentration.

The primers used for RT and amplification of BBMV RNA were BBMV-spe- cific primers Bract1 (5' GAC ATC ACC AAA TTT GAA TGG CAC ATG G 3') and Bract2 (5' CCA TTA TCA CTC GAT CAA TAC CTC ACA G 3'). These primers were designed to amplify a 604-bp product, including the $\mathrm{C}$ terminus of the coat protein and the $3^{\prime}$ untranslated region of the BBMV genome (3).

First-strand cDNA was synthesized from 1 to $2 \mu \mathrm{g}$ of RNA with a Pharmacia (Uppsala, Sweden) first-strand cDNA kit. The PCR reaction mix $(50 \mu \mathrm{l})$ contained $30 \mathrm{pmol}$ of each primer, $200 \mu \mathrm{M}$ each dNTP, $20 \mathrm{mM}$ Tris- $\mathrm{HCl}(\mathrm{pH} 8.75), 10 \mathrm{mM} \mathrm{KCl}, 10 \mathrm{mM}$ $\left(\mathrm{NH}_{4}\right)_{2} \mathrm{SO}_{4}, 2 \mathrm{mM} \mathrm{MgSO}, 1 \mathrm{mg}$ of bovine serum albumin per $\mathrm{ml}, 0.15 \%$ Triton $\mathrm{X}$ $100,1 \mu \mathrm{l}$ of cDNA reaction mix, and 1.25 units of Taq polymerase (Perkin-Elmer Cetus, Norwalk, CT). The mix was heated at $94^{\circ} \mathrm{C}$ for $5 \mathrm{~min}$, followed by 30 cycles of $94^{\circ} \mathrm{C}$ for $20 \mathrm{~s}, 55^{\circ} \mathrm{C}$ for $20 \mathrm{~s}$, and $72^{\circ} \mathrm{C}$ for $20 \mathrm{~s}$, and, finally, 1 cycle of $72^{\circ} \mathrm{C}$ for $10 \mathrm{~min}$.

CMV RNA was amplified by RT-PCR with primers made to conserved regions of the coat protein cistron (2). The cycling parameters consisted of an initial denaturation of $94^{\circ} \mathrm{C}$ for $5 \mathrm{~min}$, followed by 30 cycles of $94^{\circ} \mathrm{C}$ for $45 \mathrm{~s}, 50^{\circ} \mathrm{C}$ for $20 \mathrm{~s}$, and $72^{\circ} \mathrm{C}$ for $2 \mathrm{~min}$, and, finally, 1 cycle of $72^{\circ} \mathrm{C}$ for 5 min.

Preparation of probes and Southern blot analysis of PCR products. The 604bp product amplified from BBMV clone pB1 (3) with primers Bract1 and Bract2 and the 500-bp PCR product amplified from a banana-infecting strain of CMV were used as probes. The amplified products were Wizard purified (Promega, Madison, WI) from a $1 \%$ agarose gel and labeled with digoxigenin (DIG) with random primers, as specified by the manufacturer (Boehringer $\mathrm{GmbH}$, Mannheim, Germany).

For Southern blot analysis, amplified products were separated on a $1 \%$ agarose gel and transferred to $\mathrm{N}^{+}$nylon membrane (Amersham Corp., Arlington Heights, IL). The membranes were prehybridized at $65^{\circ} \mathrm{C}$ for $3 \mathrm{~h}$ and hybridized with the DIG-dUTPlabeled probe for $16 \mathrm{~h}$ at $65^{\circ} \mathrm{C}$. The DIG label was detected by chemiluminescence with CSPD (Boehringer Mannheim) substrate following the manufacturers instructions.

Cloning, sequencing, and analysis of PCR products. The PCR products were ligated directly into the T-tailed vector pGEM-T (Promega) and transformed into Escherichia coli DH5 $\alpha$ cells (6). Transformants were 
screened by digesting recombinant plasmids with NotI and NcoI. Potential recombinants were sequenced with an Applied Biosystems (Foster City, CA) 373A automatic DNA sequencer and universal forward and reverse primers. The sequences were analyzed by the PileUp and DISTANCES programs of the Wisconsin Genetics Computer Group program package, version 7.3 (5).

\section{RESULTS}

Symptoms and electron microscopy. The banana samples used in this study were collected from three locations in India: the Coimbatore and Tiruchchirappalli regions (Tamil Nadu Province) and the Pune region (Maharashtra State). In the Coimbatore region, typical symptoms of BBMV were observed in banana cvs. Musa balbisiana, Klue Terapod, Cavendish, and Bluggoe and included distinctive streaks on the bract of the banana inflorescence and a mosaic on the petiole of the leaf. In the Tiruchchirappalli and Pune regions, typical symptoms of BBMV were not observed on any banana plants examined. However, banana cvs. Pisang Awak, Poovan, and Matti hybrid showed symptoms similar to those caused by CMV, including a severe mosaic on the leaf lamina and a mottled pattern on the petioles of the leaves. Some of the severely infected leaves were distorted, and infected plants appeared stunted.

Partially purified virus preparations of isolates from M. balbisiana and Pisang Awak from the Coimbatore and Tiruchchirappalli regions, respectively, contained flexuous rodshaped potyvirus-like particles, measuring approximately $760 \times 12 \mathrm{~nm}$. Sap dips from infected plants growing in all three regions contained morphologically similar potyviruslike particles. Interestingly, more particles were observed in sap dips from banana plants growing in the Maharashtra State than in samples taken from Tamil Nadu Province. CMV-like particles were not observed in any samples examined.

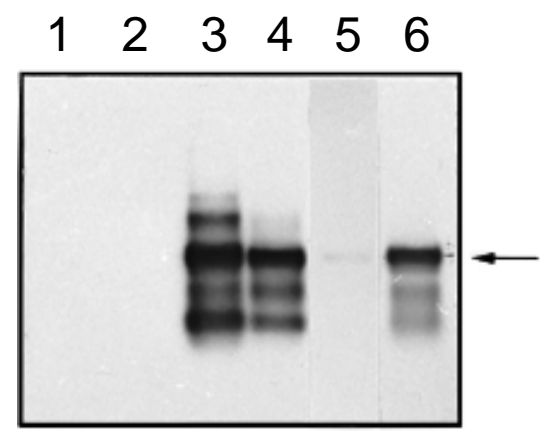

Fig. 1. Southern blot analysis of healthy and banana bract mosaic virus-infected banana material. Lane 1, buffer control; lane 2, healthy banana; lane 3, cv. Musa balbisiana (Coimbatore, India) isolate; lane 4, cv. Klue Terapod (Coimbatore, India) isolate; lane 5, cv. Pisang Awak (Tiruchchirappalli, India) isolate; lane 6, cv. B1-B2positive control (Philippines). Arrow indicates $600-b p$ product.
Amplification, cloning, and Southern blot analysis. Total RNA was extracted from samples of M. balbisiana, Klue Terapod, Pisang Awak, and healthy banana and tested for the presence of BBMV by PCR with primers Bract1 and Bract2. A product of the expected size (604 nt) was strongly amplified from the M. balbisiana and Klue Terapod samples and weakly amplified from the Pisang Awak sample. No products were amplified from healthy banana plants. The PCR products were Southern blotted onto Hybond $\mathrm{N}^{+}$and hybridized with a DIGlabeled BBMV-specific probe. The probe hybridized specifically with the 604-bp product from the M. balbisiana and Klue Terapod samples from the Coimbatore region and from the Pisang Awak sample from the Tiruchchirappalli region (Fig. 1). No hybridization occurred with the healthy banana sample.

The PCR products from $M$. balbisiana and Klue Terapod were cloned directly into pGEM-T. The concentration of the PCR product amplified from the Pisang Awak sample was insufficient to allow direct cloning. Therefore, BBMV was purified from $30 \mathrm{~g}$ of infected Pisang Awak material, and the extracted RNA was used as a template for PCR. A strong band, approximately $600 \mathrm{bp}$, was amplified that hybridized specifically with the DIG-labeled BBMV-specific probe. This PCR product was cloned into pGEM-T.

The samples from India also were tested for the presence of CMV by PCR with primers made to conserved regions of the coat protein gene that amplify a 500-bp product (2). The PCR products were Southern blotted on Hybond $\mathrm{N}^{+}$and hybridized with a DIGlabeled CMV-specific probe. The probe hybridized with an amplified band of the expected size from Klue Terapod showing characteristic BBMV symptoms and from BBMV-infected Pisang Awak with CMVlike symptoms but not from $M$. balbisiana showing characteristic BBMV symptoms (data not shown).

Sequence analysis. Three clones from each of the Coimbatore isolates (from $M$. balbisiana and Klue Terapod) and the Tiruchchirappalli isolate (from Pisang Awak) were sequenced, and the sequences within each isolate were identical. The nucleotide sequences of these three Indian isolates were compared with the published Philippines isolate (GenBank accession no. S77912) using the DISTANCES program (Table 1). There was $98.7 \%$ sequence homology between the M. balbisiana and Klue Terapod isolates from Coimbatore. The Pisang Awak isolate from Tiruchchirappalli had $95.9 \%$ homology with the Klue Terapod isolate and $96.9 \%$ homology with the M. balbisiana isolate. When compared with the Philippines isolate of BBMV, the M. balbisiana, Klue Terapod, and Pisang Awak isolates had 97.6, 96.6, and 99\% homology, respectively (Table 1).

The sequences were translated into the open reading frame reported by Bateson and Dale (3) and were compared by the DISTANCES program, and in most instances, the amino acid homologies were higher than the corresponding nucleotide homologies (Table 1). The Pisang Awak and Philippines isolates had identical amino acid sequences, compared to $99 \%$ homology at the nucleotide level. When comparing the M. balbisiana and Pisang Awak isolates, there were 13 base changes over 432 bases ( $97 \%$ homology) and only 1 amino acid change over 144 amino acids $(99.3 \%$ homology) (Figs. 2 and 3). These results indicate that most of the base changes between these isolates were silent and did not alter the amino acid sequence of the BBMV coat protein. However, amino acid homologies between Klue Terapod and M. balbisiana $(97.9 \%)$ were lower than the nucleotide sequence homology $(98.7 \%)$ and were due to base changes at positions 158,234 , and 339 (Fig. 2) that resulted in 3 amino acid changes at positions 53, 78, and 113 (Fig. 3).

\section{DISCUSSION}

We have identified BBMV in banana plants growing in India based on symptomatology, electron microscopy, Southern blot, and nucleotide sequence analysis. BBMV also was detected in some banana cultivars that showed CMV-like symptoms and not the characteristic bract mosaic symptom.

The nucleotide and deduced amino acid sequences of BBMV isolates from cvs. $M$. balbisiana, Klue Terapod, and Pisang Awak from India were compared with the pub-

Table 1. Nucleotide and amino acid sequence homologies of the C-terminal region of the coat protein-coding and $3^{\prime}$ untranslated regions of a banana bact mosaic virus (BBMV) isolate from the Philippines (Phil) and three isolates from southern India: from cvs. Musa balbisiana (CMbal) and Klue Terapod (CKlue) from the Coimbatore region and from cv. Pisang Awak (TPAwa) from the Tiruchchirappalli region $^{\mathrm{a}}$

\begin{tabular}{lcccc}
\hline & Phil & CMbal & CKlue & TPAwa \\
\hline Phil & & 97.6 & 96.6 & 99.0 \\
CMbal & $99.3^{\mathrm{b}}$ & & 98.7 & 96.9 \\
CKlue & $97.2^{2}$ & 97.9 & & 95.9 \\
TPAwa & 100.0 & 99.3 & 97.2 & \\
\hline
\end{tabular}

a Figures above the diagonal refer to the nucleotide sequences; figures below the diagonal refer to the amino acid sequences.

${ }^{b}$ Values indicate the percent sequence homology of the C-terminal 144 amino acids of the BBMV coat protein-coding region. 


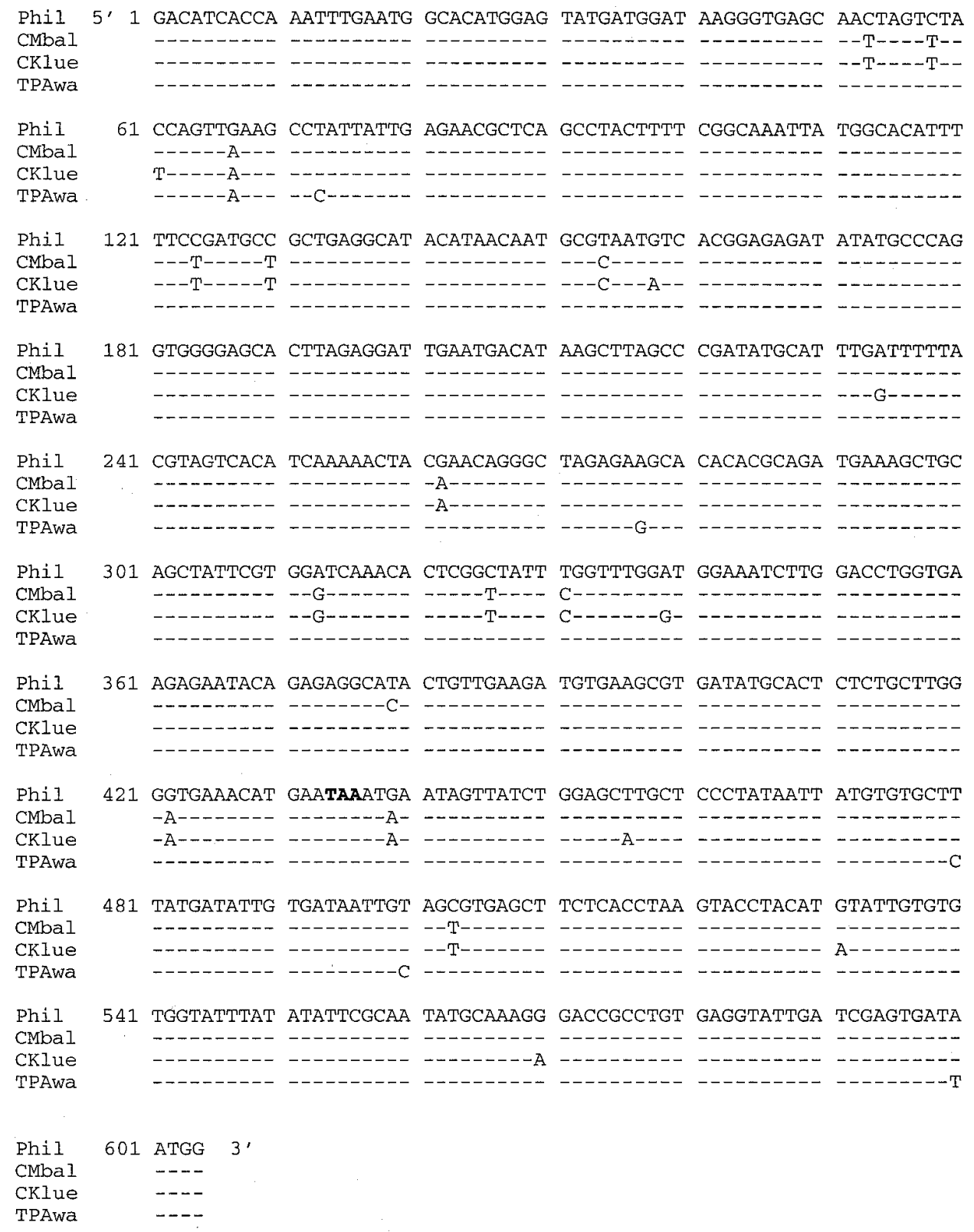

Fig. 2. Nucleotide sequence alignment of the C-terminal region of the coat protein-coding and $3^{\prime}$ untranslated regions of a banana bract mosaic virus isolate from the Philippines (Phil) and three isolates from southern India: from cvs. Musa balbisiana (CMbal) and Klue Terapod (CKlue) from the Coimbatore region and from cv. Pisang Awak (TPAwa) from the Tiruchchirappalli region. The conserved stop codon at nucleotide 434 is in bold.

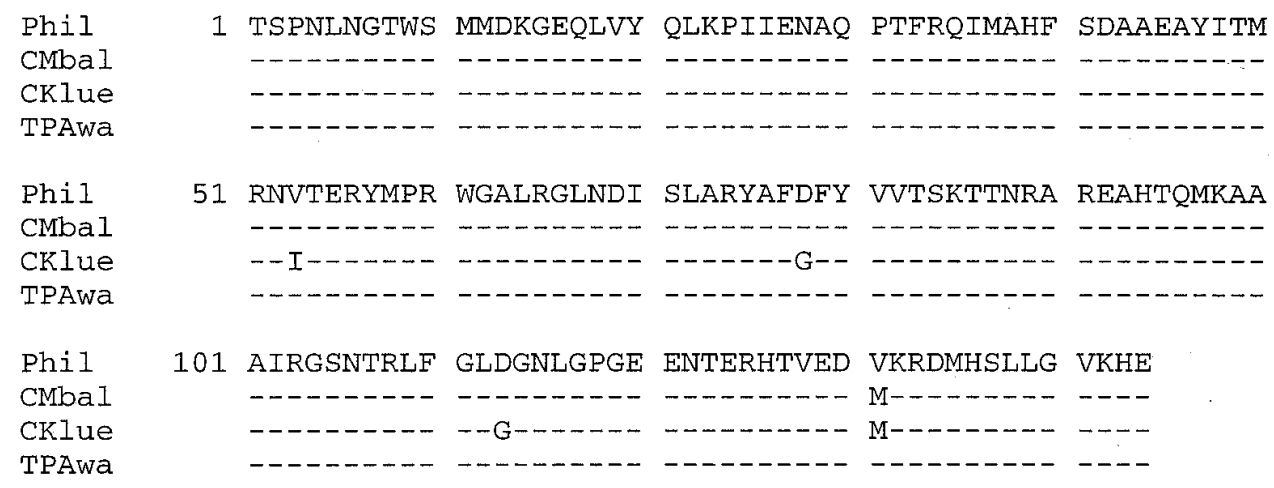

Fig. 3. Amino acid sequence alignment of the C-terminal region of the banana bract mosaic virus coat protein-coding region from a Philippine isolate (Phil) and three isolates from southern India: from cvs. Musa balbisiana (CMbal) and Klue Terapod (CKlue) from the Coimbatore region and from cv. Pisang Awak (TPAwa) from the Tiruchchirappilli region. 
lished sequence of the BBMV isolate from the Philippines (3). There was greater than 95.9\% sequence homology among the three isolates from India. Interestingly, the Philippine and Pisang Awak BBMV isolates were more similar to each other than to either of those from M. balbisiana or Klue Terapod. The Philippines and Pisang Awak isolates showed $99 \%$ similarity at the nucleotide level and were identical at the amino acid level. The relatively recent appearance of the characteristic bract mosaic symptoms in bananas in the Philippines together with the sequence comparisons reported in this paper suggest that BBMV may have moved from India to the Philippines rather than vice versa. However, it will be necessary to sequence a number of other isolates from India, the Philippines, and possibly other regions where BBMV may occur to investigate the variability of BBMV sequences within and between regions.

CMV was associated with BBMV infections that had CMV-like symptoms and also was associated with some, but not all, of the BBMV-infected banana plants showing characteristic bract mosaic symptoms. It appears, therefore, that CMV is not essential for the development of the characteristic BBMV symptoms. CMV may mask the development of the characteristic symptoms of BBMV in some banana cultivars, or alternatively, the CMV-like symptoms observed in the Tiruchchirappalli region may be due to a different strain of BBMV. CMV and banana streak badnavirus can cause a wide range of symptoms in banana, depending on the banana cultivar, virus strain, and environmental conditions $(9,10$, 15). Therefore, the mild mosaic symptoms on the younger leaves of BBMV-infected bananas (13) could be confused with the mosaic symptoms produced by $\mathrm{CMV}$ on infected bananas (8).

BBMV previously had been reported only in the Philippines (8) and, thus, posed a considerable quarantine risk to other ba- nana-growing regions. This report indicates that BBMV may be more widespread than originally thought but not yet identified because of confusing symptomatology, dual infections with other banana viruses, and the inherent difficulties in detecting virions in banana sap. Filamentous particles have been reported from bananas growing in other regions, including Costa Rica, Uganda, Ghana, Zanzibar, and South Africa (11, 16) but have not yet been identified.

We have confirmed the presence of BBMV in India and also detected BBMV in plants showing symptoms similar to those caused by CMV. A reliable diagnostic assay for the detection of BBMV is required to determine the distribution of BBMV in bananagrowing regions and enable indexing of banana germplasm and planting material prior to interregional transfer.

\section{ACKNOWLEDGMENTS}

The financial assistance of IPGRI is gratefully acknowledged. We thank P. Vidyasekeran and N. Ragupathi from the Department of Plant Pathology, Tamil Nadu Agricultural University, Coimbatore, India, for their assistance in collecting plant material.

\section{LITERATURE CITED}

1. Anonymous. 1992. International network for the improvement of banana and plantain. Pages 29-33 in: Annual Report 1992. International Network for the Improvement of Banana and Plantain, Montpellier, France.

2. Bariana, H. S., Shannon, A. L., Chu, P. W. G., and Waterhouse, P. M. 1994. Detection of five seedborne legume viruses in one sensitive multiplex polymerase chain reaction test. Phytopathology 84:1201-1205.

3. Bateson, M. F., and Dale, J. L. 1995. Banana bract mosaic virus: Characterisation using potyvirus specific degenerate PCR primers. Arch. Virol 140:515-527.

4. Chang, S., Puryear, J., and Cairney, J. 1993. A simple and efficient method for isolating RNA from pine trees. Plant Mol. Biol. Rep. 11:113116.

5. Devereaux, J., Haeberli, P., and Smithies, O. 1984. A comprehensive set of sequence analysis programs for the VAX. Nucleic Acids Res. 12:387-395.
6. Dower, W. J., Miller, J. F., and Ragsdale, C. W. 1988. High efficiency transformation of $E$. coli by high voltage electroporation. Nucleic Acids Res. 16:6127-6145.

7. Espino, T. M., Exconde, S. B., Zipagan, F. B., and Espino, R. R. C. 1990. Banana bract mosaic, a new disease of banana. II. Isolation and purification for monoclonal antibody production. Philipp. Agric. 73:61-68.

8. Frison, E. A., and Putter, C. A. J. 1989. FAO/ IBPGR Technical Guidelines for the Safe Movement of Musa Germplasm. Food and Agriculture Organisation of the United Nations, Rome/International Board for Plant Genetic Resources, Rome.

9. Hu, J. S., Li, P. H., Barry, K., and Wang, M. 1995. Comparison of dot blot, ELISA, and RT-PCR assays for detection of two cucumber mosaic virus isolates infecting banana in Hawaii. Plant Dis. 79:902-906.

10. Jones, D. R., and Lockhart, B. E. L. 1993 Musa Disease Fact Sheet 1: Banana Streak Disease. International Network for the Improvement of Banana and Plantain, Montpellier, France.

11. Lockhart, B. E. L. 1994. Development of detection methods for banana streak virus. Pages 20-21 in: Annual Report 1994. International Network for the Improvement of Banana and Plantain, Montpellier, France.

12. Magnaye, L. V., and Espino, R. R. C. 1990. Banana bract mosaic, a new disease of banana. I. Symptomatology. Philipp. Agric. 73: 55-59.

13. Munez, A. R. 1992. Symptomatology, transmission and purification of banana bract mosaic virus (BBMV) in 'Giant Cavendish' banana. M.S. thesis. University of the Philippines, Los Baños.

14. Rivera, R., Ramirez, P., and Pereira, R. 1993. Preliminary characterisation of viruses infecting banana in Costa Rica. Pages 63-68 in: Proc. Workshop Biotechnol. Appl. Banana Plantain Improve. International Network for the Improvement of Banana and Plantain, Montpellier, France.

15. Singh, Z., Jones, R. A. C., and Jones, M. G. K. 1995. Identification of cucumber mosaic virus subgroup I isolates from banana plants affected by infectious chlorosis disease using RT-PCR. Plant Dis. 79:713-716.

16. Tushmereirwe, W. K., Karamura, E. B., and Karyeija, R. 1996. Banana streak virus (BSV) and an associated filamentous virus (unidentified) disease complex of Highland bananas in Uganda. Infomusa 5:9-12. 